\title{
Effects of changes in Italian bioenergy promotion schemes for agricultural biogas projects: insights from a regional optimization model
}

D. Chinese, P. Patrizio, G. Nardin

DIEGM - Dipartimento di Ingegneria Elettrica, Gestionale e Meccanica - University of Udine, 33100 Udine, Italy

\begin{abstract}
Italy has witnessed an extraordinary growth in biogas generation from livestock effluents and agricultural activities in the last few years as well as a severe isomorphic process, leading to a market dominance of $999 \mathrm{~kW}$ power plants owned by "entrepreneurial farms". Under the pressure of the economic crisis in the country, the Italian government has restructured renewable energy support schemes, introducing a new program in 2013. In this paper, the effects of the previous and current support schemes on the optimal plant size, feedstock mix and profitability were investigated by introducing a spatially explicit biogas supply chain optimization model, which accounts for different incentive structures. By applying the model to a regional case study, homogenization observed to date is recognized as a result of former incentive structures. Considerable reductions in local economic potentials for agricultural biogas power plants without external heat use, are estimated. New plants are likely to be manure-based and due to the lower energy density of such feedstock, wider supply chains are expected although optimal plant size will be smaller. The new support scheme will therefore most likely eliminate past distortions but also slow down investments in agricultural biogas plants.
\end{abstract}

Keywords: Agricultural biogas; Supply chain optimization; Bioenergy support schemes. 


\section{Nomenclature}

Sets

T Feedstock type

S Technology size class

L Feasible locations (nodes)

A Feasible links

Subscripts

$t \quad$ Feedstock type

$S \quad$ Technology size class

$i, j, k \quad$ Feasible locations (nodes)

$(i, j) \quad$ Feasible links

Superscripts

$A D \quad$ Anaerobic Digester

$B \quad$ Biomass (including energy crops and animal byproducts)

$B G \quad$ Biogas

BYP Byproducts from animal breeding

D Digestate

ECP Energy Crops

FI Feed-In Tariff

GC Green Certificates

$H \quad$ Heat

ICE Internal Combustion Engine

$N \quad$ Nitrogen

ORC Organic Rankine Cycle

$P \quad$ Power

PLANT Energy conversion plant 


\begin{tabular}{|c|c|}
\hline TECH & Generic conversion technology \\
\hline disp_D & Disposal (of digestate) \\
\hline harv & Harvesting \\
\hline inv & Capital investment \\
\hline$l_{-} D$ & Loading (of digestate) \\
\hline$l u \_B$ & Loading and Unloading (of biomass) \\
\hline maint & Maintenance \\
\hline$l a b$ & Labour \\
\hline purc_BYP & Purchasing (of animal byproducts) \\
\hline spread_D & Spreading (of digestate) \\
\hline $\operatorname{tr} \_B$ & Transport (of biomass) \\
\hline $\operatorname{tr} \_D$ & Transport (of digestate) \\
\hline \multicolumn{2}{|l|}{ Parameters } \\
\hline$\alpha$ & Heat recovery fraction from ICE available for bottoming cycle (dimensionless) \\
\hline$\delta^{\mathrm{H}}$ & Plant self- consumption of heat (dimensionless) \\
\hline$\delta^{P}$ & Plant self- consumption of electricity (dimensionless) \\
\hline$\eta_{S}^{I C E}$ & Efficiency of internal combustion engine - ICE (dimensionless) \\
\hline$\eta^{O R C}$ & Efficiency of bottoming Organic Rankine Cycle - ORC (dimensionless) \\
\hline$\rho_{j}$ & Radius of the $j$-th supply area $[\mathrm{km}]$ \\
\hline$\tau$ & Tortuosity factor (dimensionless) \\
\hline$I$ & Annual interest rate (dimensionless) \\
\hline$M^{P L A N T}$ & Upper bound value for overall electric capacity of power plant (ICE and ORC) $[\mathrm{kW}]$ \\
\hline$N_{t}^{B Y P}$ & Nitrogen content in byproduct $t\left[\mathrm{Kg}_{\mathrm{N}} \mathrm{t}^{-1}\right]$ \\
\hline$N^{E C P}$ & Nitrogen content in energy crop $\left[\mathrm{Kg}_{\mathrm{N}} \mathrm{t}^{-1}\right]$ \\
\hline$N_{j}^{\max }$ & Maximum permissible amount of nitrogen to be spread in $j\left[\mathrm{~kg}_{N} /\right.$ year $]$ \\
\hline$S B_{S}$ & Capacity upper bound of size class $s[\mathrm{~kW}]$ \\
\hline
\end{tabular}



$b^{T E C H} \quad$ Intercept of investment cost curve for technology TECH $[€]$
$c^{\text {spread_D }} \quad$ Unit cost of digestate spreading (referred to its Nitrogen content) $\left[€ \mathrm{~kg}_{\mathrm{N}}^{-1}\right]$
$c^{\text {harv } E C P} \quad$ Unit cost of growing and harvesting energy crops $\left[€ \mathrm{t}^{-1}\right]$
$c^{\text {ins_PLANT }} \quad$ Unit cost of insurance and warding $\left[€ \mathrm{kWh}^{-1}\right]$
$c^{l \_D} \quad$ Unit cost of digestate loading (referred to Nitrogen content) [ $\left.€ \mathrm{~kg}_{\mathrm{N}}^{-1}\right]$
$c^{l u \_B} \quad$ Unit cost of biomass loading and unloading $\left[€ \mathrm{t}^{-1}\right]$
$c^{\text {maint_PLANT }}$ Unit cost of plant maintenance $\left[€ \mathrm{kWh}^{-1}\right]$
$c_{S}^{l a b_{-} P L A N T} \quad$ Labour cost coefficient depending on plant size class [ $€$ year $\left.^{-1}\right]$
$c_{t}^{\text {purc_BYP }} \quad$ Purchase cost of different animal byproduct types $\left[€ \mathrm{t}^{-1}\right]$
$c_{t}^{t r} r_{-} \quad$ Unit cost of transporting biomass $\left[€ \mathrm{t}^{-1} \mathrm{~km}^{-1}\right]$
$c_{t}^{t r_{-} D} \quad$ Unit cost of transporting digestate $\left[€ \mathrm{~kg}_{\mathrm{N}} \mathrm{km}^{-1}\right]$
dist $_{i, j} \quad$ Distance between $i$ th and $j$ th nodes $[\mathrm{km}]$
$d_{t}^{B Y P} \quad$ Digestate production rate for byproduct $t$ (dimensionless)
$d^{E C P} \quad$ Digestate production rate for considered energy crop (dimensionless)

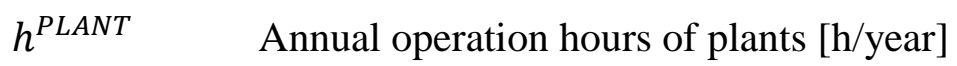
$k^{B G} \quad$ Average calorific value of biogas $\left[\mathrm{kWh} \mathrm{Nm}^{-3}\right]$
$m^{T E C H} \quad$ Slope of investment cost curve for generic technology $T E C H\left[€ \mathrm{~kW}^{-1}\right]$
$\operatorname{tar}^{G C} \quad$ Equivalent feed in tariff with Green Certificates under the 2009 support scheme $\left[€ \mathrm{kWh}^{-1}\right]$
$\operatorname{tar}^{F I} \quad$ Feed In Tariff under the 2012 support scheme $\left[€ \mathrm{kWh}^{-1}\right]$
$\operatorname{tar}_{S}^{B Y P} \quad$ Feed In Tariff /Premium for animal byproducts based plants under the 2012 support scheme, depending on plant size class $s \quad\left[€ \mathrm{kWh}^{-1}\right]$
$\operatorname{tar}_{s}^{E C P} \quad$ Feed In Tariff /Premium for energy crops (maize silage) based plants under the 2012 incentive scheme, depending on plant size class $s \quad\left[€ \mathrm{kWh}^{-1}\right]$
$v s_{t}^{B Y P} \quad$ Volatile solid content in animal byproducts, depending on type $t$ (dimensionless) 
$v S^{E C P} \quad$ Volatile solid content in energy crop (dimensionless)

$y_{t}^{B G_{-} B Y P} \quad$ Biogas yield of animal byproducts, depending on type $\left[\mathrm{Nm}^{3} \mathrm{t} \mathrm{VS}^{-1}\right]$

$y^{B G_{-} E C P} \quad$ Biogas yield of energy crop $\left[\mathrm{Nm}^{3} \mathrm{t} \mathrm{VS}^{-1}\right]$

Variables

$B G_{j} \quad$ Total annual biogas production at node $j\left[\mathrm{Nm}^{3} \mathrm{yr}^{-1}\right]$

$C_{j}^{\text {purc_BYP }} \quad$ Annual purchase cost of animal byproduct $\left[€ \mathrm{yr}^{-1}\right]$

$C_{j}^{h a r v_{-} E C P} \quad$ Annual production and harvesting costs of energy crop at node $j\left[€ \mathrm{yr}^{-1}\right]$

$C_{j}^{d i s p_{-} D} \quad$ Total annual cost of digestate disposal at node $j\left[€ \mathrm{yr}^{-1}\right]$

$C_{j}^{i n v} \quad$ Annual equivalent cost of capital investment at node $j\left[€ \mathrm{yr}^{-1}\right]$

$C_{j}^{l a b} \quad$ Total annual direct labor cost at site $j\left[€ \mathrm{yr}^{-1}\right]$

$C_{j}^{\text {main }} \quad$ Total annual maintenance cost at site $j[€ / \mathrm{yr}]$

$C_{(i, \bar{j}, t)}^{t r} \quad \quad$ Total annual cost of transporting biomass of type $t$ from node $i$ to node $j\left[€ \mathrm{yr}^{-1}\right]$

$C_{(i, j)}^{t r-D} \quad$ Total annual cost of transporting digestate of type $t$ from node $i$ to node $j\left[€ \mathrm{yr}^{-1}\right]$

$E l_{j}^{F I}, E l_{j}^{G C} \quad$ Annual net electricity production remunerated with FI or GC, respectively, under the 2009 tariff scheme, at node $j\left[\mathrm{kWh} \mathrm{yr}^{-1}\right]$

$E l_{s, j}^{E C P}, E l_{s, j}^{B Y P}$ Annual net electric production remunerated with ECP or BYP premiums, respectively, under the 2012 tariff scheme, at node $j$ [ $\mathrm{kWh} \mathrm{yr}^{-1}$ ]

$E l_{j}^{G R O S S} \quad$ Annual gross electricity production at node $j\left[\mathrm{kWh} \mathrm{yr}^{-1}\right]$

$E l_{j}^{I C E} \quad$ Annual gross electricity production from ICE at node $j\left[\mathrm{kWh} \mathrm{yr}^{-1}\right]$

$E l_{j}^{N E T} \quad$ Yearly net electricity production at node $j\left[\mathrm{kWh} \mathrm{yr}^{-1}\right]$

$E l_{j}^{O R C} \quad$ Yearly electricity production from ORC technology at node $j\left[\mathrm{kWh} \mathrm{yr}^{-1}\right]$

$H_{j}^{I C E} \quad$ Yearly heat recovery from ICE technology at node $j\left[\mathrm{kWh} \mathrm{yr}^{-1}\right]$

$H_{j}^{O R C} \quad$ Yearly heat production with ORC technology at node $j\left[\mathrm{kWh} \mathrm{yr}^{-1}\right]$ 
$Q_{t, i, j}^{B} \quad$ Quantity of biomass of type $t$ transported from node $i$ to node $j$ [t/year]

$Q_{t, i, j}^{B Y P} \quad$ Quantity of animal byproduct of type $t$ transported from node $i$ to node $j$ [t/year]

$Q_{t, j}^{B Y P} \quad$ Quantity of animal byproduct of type $t$ consumed in node $j$ [t/year]

$Q_{i, j}^{E C P} \quad$ Quantity of energy crop transported from node $i$ to node $j$ [t/year]

$Q_{j}^{E C P} \quad$ Quantity of energy crop consumed in node $j$ [t/year]

$Q_{j}^{\text {harv_ECP }} \quad$ Quantity of energy crop harvested in node $j$ [t/year]

$Q_{t, j}^{\text {purc_BYP }} \quad$ Quantity of animal byproduct of type $t$ collected in node $j$ [t/year]

$Q_{i, j}^{N_{-} D} \quad$ Nitrogen content of digestate transported from node $i$ to node $j$ [kg/year]

$Q_{j}^{N \_s p r e a d} \quad$ Nitrogen content of digestate spread in location $j[\mathrm{~kg} / \mathrm{year}]$

$R_{j} \quad$ Total annual revenues [€]

$S_{j}^{I C E} \quad$ Capacity of ICE installed in node $j[\mathrm{~kW}]$

$S_{j}^{O R C} \quad$ Capacity of ORC installed in node $j[\mathrm{~kW}]$

$S_{j}^{\text {PLANT }} \quad$ Total power generation capacity of the plant installed in node $j[\mathrm{~kW}]$

$S_{j}^{T E C H} \quad$ Capacity of the generic technology $T E C H$ installed in node $j[\mathrm{~kW}]$

$X_{j}^{A D}, X_{j}^{I C E}, X_{j}^{O R C}, X_{j}^{T E C H} \quad$ Binary variables accounting for the installation of conversion technologies $A D, I C E, O R C, T E C H$ at site $j$

$X S_{S, j}^{P L A N T} \quad$ Binary variable identifying plant in $j$ as belonging to size class $s$

$X S_{s, j}^{I C E} \quad$ Binary variable identifying ICE in $j$ as belonging to size class $s$

$X T_{j}^{F I}, X T_{j}^{G C}, X T_{s, j}^{E C P}, X T_{s, j}^{B Y P}$ Binary variables controlling tariff schemes and classes under which energy is remunerated, if opportune depending on size class $s$

$X B_{j} \quad$ Binary variable accounting for biomass share limits for energy tariff application

Other acronyms used in text

EEG Erneuerbare-Energien-Gesetz, German Renewable Energy Act

GHG Greenhouse gases 


$\begin{array}{ll}\text { GSE } & \text { Gestore Servizi Energetici }- \text { Italian National Grid Operator } \\ \text { MILP } & \text { Mixed Integer Linear Programming } \\ \text { RES } & \text { Renewable Energy Sources } \\ \text { RES-E } & \text { Electricity from Renewable Energy Sources } \\ \text { TGC } & \text { Tradable Green Certificates }\end{array}$

\section{Introduction}

In the last few years, electricity generation from agricultural and landfill biogas in Europe has increased from approximately 17 TWh in 2006 (Eurobserv'er, 2008) to almost 36 TWh in 2011 (Eurobserv'er, 2012). In Italy, installed capacity and yearly electricity production increased by a factor of approximately 9 between 2007 and 2011 (Table 1).

Table 1. Evolution of biogas-to-electricity plants from livestock effluents and agricultural activities in Italy, own elaboration based on most recent data available from GSE $(2008,2009,2010,2011)$

Production values recently achieved in Italy are just a fraction of potentials: Tricase and Lombardi (2009) estimated that animal breeding sewage digestion alone could generate up to $3.6 \mathrm{TWh} / \mathrm{year}$, which is approximately twice as much as total production levels in 2011.

In the near future, it would thus be technically feasible to expand agricultural biogas generation beyond current production levels. Whether expanding agricultural biogas generation would also be economically feasible depends largely on promotion schemes. In fact, several studies from different countries (e.g., Yiridoe et al., 2009; Gebrezghaber et al., 2010) confirm that, even considering cobenefits from cogenerated heat or digestate exploitation, power generation from agricultural biogas plants is profitable only when some form of incentive is available. Indeed, in the recent expansion of agricultural biogas in Italy, incentives were decisive. 


\subsection{The evolution of biogas support programs in Italy}

The first incentives for electricity generation from agricultural biogas were introduced in Italy before the liberalization of energy markets with the resolution known as CIP6 (Provvedimento CIP6/1992, April 29, 1992). As summarized in Table 2, the subsidy consisted of a Feed In Tariff (FIT) made up of an avoided cost and an investment grant component. The CIP6 program initiated biogas generation in the country, with an increase from nearly zero before 1992 to some $400 \mathrm{GWh}$ in 1997, almost completely from landfills (Tricase and Lombardi, 2009).

Agricultural biogas generation remained almost nil until a first substantial rise in the early 2000s, determined by the transposition of the European Directive 96/92/EC into Italian Law with Decree Law 79/99 of February 19, 1999. A quota-obligation-based renewable energy support mechanism was started with the introduction of Tradable Green Certificates (TGCs). The regulation of the agronomic use of livestock effluents, implemented between 1999 and 2006 to transpose the European Directive 91/676/EC, also contributed to the development of digesters.

However, not until the introduction of the Feed In Tariff and its final determination at $280 € / \mathrm{MWh}$ with the Law 99/23 July 2009 did agricultural biogas production receive a real boost, mirrored by the three-figure percent growth reported in Table 1 for the years 2010 and 2011.

As summarized in Table 2, the same regulations also modified TGC by extending their validity period to 15 years and by differentiating their value by technology, introducing a banding factor of 1.8 for bioenergy from short supply chains (supply radius below $70 \mathrm{~km}$ ). As a result, according to data from the GSE on certificate buyback prices and on power wholesale prices, average remuneration for biogas power between 2011 and 2013 was $223 € / \mathrm{MWh}$.

While the TGC option was also theoretically available for plants below the FIT eligibility threshold of $1 \mathrm{MW}$, FITs were clearly preferable both for the sake of profitability and of lower risk. 
Recommendations for RES support reported in the literature (Haas et al., 2011) suggest that distortions may arise when profitability expected at low risk (as in the case of FITs) is higher, resulting in higher additional costs finally paid by consumers.

Table 2. Policy changes in agricultural biogas support in Italy

Indeed, an analysis of the Italian biogas market based on neo-institutional theory (Carrosio, 2013) highlighted that in recent years very similar typologies have become dominant in Italy, i.e., 999 kWe plants using a mix of animal feedstock and energy crops (mainly maize) as substrates. From an organizational viewpoint, Carrosio (2013) classified these plants as "entrepreneurial farms" that do not have significant connections with local communities and do not make use of the heat they produce. Such isomorphic process would result in economic and environmental inefficiencies, increasing the cost of corn products for fodder and emissions from the transport of biomass from farther areas to supply oversized plants.

While previous support schemes had been effective in promoting investment, changes were required as an intense debate about incentives arose in the Italian media. At a time of economic stagnation, public opinion focused on allegedly high costs of renewable energy support charged to consumers (Galeotti, 2012). As shown in Table 3, targets for electricity generation from RESs for 2011 according to the national implementation of EU Directive 2009/28/CE had been exceeded for most sources. RES-E targets had been fixed as shares of the total gross consumption of electricity, where growth was below forecasts due to the decline of the Italian GDP and of industrial production from 2008 onwards. Absolute values of solar electricity production and of biogas electricity production were, however, larger than expected, although the latter remained well below 2020 targets. 
Table 3. Actual and target values for RES-E, particularly biomass, according to the EU Directive 2009/28/CE

In this climate, the Decree of the Minister of Economic Development of 6 July 2012 introduced an incentive structure more in line with those in force in Germany, Austria and The Netherlands (Hahn et al., 2010). In fact, as summarized in Table 2, the new biogas support policy includes:

- $\quad$ A stepped technology specific feed-in-tariff (third column of Table 2) for twenty years;

- An augmented tariff for plants using a minimum share of $30 \%$ manure, resembling similar bonuses or constraints in Austria and Germany;

- An additional bonus for high efficiency cogeneration of $40 € / \mathrm{MWh}$ (Hahn, 2010);

- $\quad$ An additional bonus of $40 € / \mathrm{MWh}$ for high efficiency cogeneration plants adopting nitrogen recovery technologies to produce fertilizers;

- $\quad$ Special bonuses for plants with capacities between $1 \mathrm{MW}$ and $5 \mathrm{MW}$ using non-food energy crops only $(20 € / \mathrm{MWh})$.

The new policy also entails a phase-out of Green Certificates. Plants commissioned before 2012 will receive proceeds from the wholesale of Green Certificates until 2015, when the Green Certificates will be replaced by a fixed feed-in premium calculated with current banding factors and equations, and with reference to current power wholesale prices.

In general, the 2012 incentive scheme is more complex than previous schemes. Basic tariffs are more generous than corresponding incentives in other countries (Hahn, 2010), and cogeneration is encouraged with higher bonuses rather than required as an eligibility constraint.

\subsection{Objectives of the research and paper structure}

The objective of this paper is to evaluate the potential effects of the most recent policy changes on agricultural biogas projects in Italy. A mathematical programming model was introduced to 
optimize plant size, feedstock supply, digestate disposal areas, and substrate mix, to compare previous and current frameworks and to highlight changes in the profitability of electricity generation from agricultural biogas.

The aim is to explore past and future chances for entrepreneurial farm models that have prevailed in the last few years in Northern Italy, i.e., agricultural biogas plants producing electricity using maize as the main feedstock. Maize silage has generally represented the dominating feedstock in biogas production, primarily due to its high cost efficiency (Delzeit, 2008). With rising food prices and resulting discussions on the competition of the land for energy or food production (Popp et al., 2014), the use of maize for biogas generation is increasingly criticized also because of its limited contribution to GHG emission reduction (Boulamanti et al., 2013). The new Italian tariff scheme did not explicitly limit the use of maize silage but assigned a special bonus for manure-based plants: the effect on the optimal biogas production feedstock mix will be investigated.

The model was developed for a regional case study, presented in section 2 , from the perspective of a local authority that plans that future biogas ventures should be approved and built which maximize wealth generation for the whole territory, an objective that goes along with satisfactory profitability for each venture. Although the case study is spatially limited, the comparison of results under biogas support schemes in force in Italy between 2009 and 2012 and from 2013 onwards, which is presented in section 3 , offers new insights on prospects for agricultural biogas in Italy and implications for policy modeling, as discussed in section 4 .

\section{Methodology, case study and model development}

Biomass supply chain design has become a central topic in bioenergy and biofuel research in the last decade. No less than five review papers on biomass-to-energy and biofuel supply chain optimization have been published in leading journals in the last three years (An et al., 2011; Gold 
and Seuring, 2011; Sharma et al., 2013; Mafakheri and Nasiri, 2014; De Meyer et al., 2014; Yue et al., in press), each listing at least eighty references, mostly dealing with mathematical modeling efforts to support supply chain analysis and optimization.

Considering the results of these reviews, there seems to be a general consensus on following facts:

- Mixed Integer Linear Programming is the most widely used methodology (Sharma et al., 2013; An et al., 2011; De Meyer et al., 2014), especially for decisions on location (Mafakheri and Nasiri, 2014), technology selection, capital and investment, production planning, and inventory management. While the limitations of MILP in terms of computational effort and determinism are recognized, its flexibility and capability for capturing global optima coherently with bottom-up engineering optimization modeling assumptions are most likely the main reasons for the success of MILP in this field.

- Regarding policy and regulatory issues, there is still very limited research on the assessment of the impact of policy choices on the capital and operational performance of the biomass supply chain (Mafakheri and Nasiri, 2014);

- Most research is focused on ligno-cellulosic biomass from forestry or energy crops, which can be used for heat and power production or for liquid biofuel production in second generation biorefineries. While the anaerobic digestion path is considered in the review framework of some authors (Sharma et al., 2014), none of the references they examine address biogas supply chains.

Researching further literature on biogas supply chains, traditional engineering economics approaches were found to be mainly used, e.g., to simulate the operation of single exemplary plants (Tahlegani and Kia, 2005; Gebrezgabher et al., 2010) and to determine the optimal plant size (Walla and Schneeberger, 2008; Gan and Smith, 2011) or the optimal timeliness for crop harvesting 
(Gunnarsson et al., 2008; Capponi et al., 2011) by repeated simulation and sensitivity analysis of continuous variables. Optimization is more often meant to improve the performance of individual biogas plants (Kana et al., 2012; Thorin et al., 2012) or sections of supply chains (Bekkering et al., 2010), rather than to analyze or design supply chains as a whole.

Few model-based approaches for a systems analysis of biogas supply chains exist to date:

- Stürmer et al. (2011) introduced a nonlinear programming model to analyze the impact of alternative substrates, machinery chains, and field distances on total substrate costs of two reference biogas plants. The model minimizes total substrate costs subject to land that is available in different distant land circles around the plants and is not spatially explicit. Indeed, the adoption of spatially explicit optimization models to analyze cost-effectiveness of energy policy is not frequent in the biomass supply chain literature as a whole (Schmidt et al., 2011).

- Delzeit et al. (2012) introduce a spatially explicit simulation framework, including a linear programming model for transport cost minimization and the iterative determination of the locations and substrate types giving maximum return on investment under German energy policy conditions for biogas generation. They also used their framework to evaluate the impact of different digestate processing options (Delzeit and Kellner, 2013).

- The German support scheme was also studied by Sorda et al. (2013), who couple an agentbased simulation model for investment decisions with GIS data to estimate additional economic capacity potential for selected German regions.

- Bojesen et al. (2014) evaluate the capacity expansion potential for biogas in Denmark, determining optimal location and production capacity by combining a location-allocation model with a production-constrained spatial interaction model. 
This paper expands research on how RES-supporting policies affect the economic performance of biogas supply chains. A bottom-up engineering optimization modeling approach (Sataye and Sanstad, 2004) is used to determine the optimal size for each plant in the area considered and to offer a cumulative view at the regional level. The problem is viewed from the perspective of central planners such as local authorities who partially control the authorization process and who are directly confronted with social acceptance issues and concerns by citizens, most commonly regarding intense traffic, bad smells, effluent management, noise, but also the actual profitability and equity of such ventures (Magnani, 2012). The region is assumed to benefit mostly from the maximization of value generation at the local system level, which would yield proportional local tax flows (Banzato, 2013) and would allow diffuse profits for more ventures, rather than from the maximization of value generation for a particular investment, which would be the primary aim for single entrepreneurs but would raise concerns about equity in local communities. Focusing on the case study described in section 2.1, for which substrate distribution and available technology options are reported, the MILP model presented in section 2.2 has been developed.

\subsection{Description of the case study and the underlying data}

The case study that was analyzed involves two provinces of Friuli-Venezia Giulia, an Italian region located at the border with Austria and Slovenia. The area includes 131 municipalities, with a surface area of $4000 \mathrm{~km}^{2}$.

Seven agricultural biogas plants currently exist in the area analyzed, with a total power generation capacity of $8272 \mathrm{~kW}$, ranging from a minimum of $526 \mathrm{~kW}$ to a maximum of $4346 \mathrm{~kW}$. The agricultural biogas plants mainly use maize silage and animal manure from local breeding farms as substrates. Yearly electricity production from biogas in Friuli Venezia Giulia amounted to $51 \mathrm{GWh}$ in 2011, while a local gross electricity consumption of $10821 \mathrm{GWh}$ was reported for the same year 
(GSE, 2011). The share of biogas electricity relative to gross electricity consumption was almost $0.5 \%$, well below both the national average and the national target shares (Table 3), even though the whole region, and especially the area examined, had a significant potential for biogas generation.

\subsubsection{Substrate potentials and biomass generation}

Within the communities examined, total useful agricultural area (UAA) is approximately 154,000 ha. Maize is a leading crop in the region of concern: approximately $60 \%$ of the arable agricultural area is yearly sown with maize (compared to $30 \%$ sown with soy and approximately $10 \%$ sown with wheat or barley), resulting in an average production of $800,000 \mathrm{t} /$ year of maize grain in the whole region (VI national agricultural census survey, ISTAT 2011). For the assessment of feedstock potentials, a yield of $60 \mathrm{t} / \mathrm{ha}$ is assumed for maize silage, based on data from local farmers. The assumption is that $10 \%$ of the total agricultural area currently sown with maize can be converted to maize silage for biogas production.

Total amounts of animal manure available in the area are estimated based on census data for livestock populations of chicken, cattle, and swine breeding farms in the region, assuming daily manure production weights per living weight reported in Table 4. A total manure production of 273,000 t/year occurs, deriving mainly from chicken (44\%) and cattle breeding (43\%). As in similar work (Pantaleo, 2013), only solid animal waste is considered, representing approximately $90 \%$ in weight of the overall animal waste, while sewage is neglected due to its low energy density.

Biogas yields from substrates depend on the type of digestion process and the temperature as well as feedstock type. In this study, a continuous mesophilic digestion process is assumed, as this type of process is adopted in most Italian biogas plants because of its relatively low internal temperatures (between $35{ }^{\circ} \mathrm{C}$ and $40{ }^{\circ} \mathrm{C}$ ) and heating requirements as well as of the stability of the process parameters (CRPA, 2008). 
Corresponding coefficients for assessing biogas generation potentials and digestate management constraints are summarized in Table 4.

Table 4. Assumptions for manure and maize silage potential assessment according to ENEA (2009) and CRPA (2012)

With these assumptions, maize silage and the total amount of the animal manure yield a total biogas potential of approximately $136,374 \mathrm{kNm}^{3} /$ year and $49,822 \mathrm{kNm}^{3} /$ year, respectively, spread over the examined municipalities as depicted in Figures 1 and 2.

Figure 1. Biogas technical potentials (B) from maize silage in the examined area

Figure 2. Biogas technical potentials (B) from animal manure in the examined area

\subsubsection{Digestate management constraints and practices}

The local implementation of the 91/676/EC directive was started only in 2003. With the regional deliberation n. 1246/2008, 68 of the 131 municipalities considered were identified as nitrate vulnerable zones (NVZs) and assigned the corresponding limit of $170 \mathrm{~kg}$ nitrogen per hectare for the application of manure fertilizer on cropland. For the remaining useful agricultural area of the region (ordinary zones), a limit of $340 \mathrm{~kg}$ nitrogen per hectare was imposed. Considering nitrate constraints and a maximum of the arable land freely available for spreading equaling $10 \%$ of the useful agricultural area currently sown with maize, estimates of maximum permissible spreading quantities of digestate for each feasible location in the area of concern represented in Figure 3 were obtained.

Figure 3. Maximum value of digestate disposal $\left(Q_{j}^{\text {maxn_spread }}\right)$ for each municipality

\subsubsection{Technology options and system boundaries}


Based on the local availability of substrates and constraints on digestate spreading, the boundaries of this study were delimited as illustrated in Figure 4.

Figure 4. Delimitation of energy and material flows considered in the study

With regard to technology selection, many system configurations are possible in both biochemical processes and technologies (see, e.g., Weiland, 2010) and in biogas utilization processes (see, e.g., Pöschl et al., 2010), leading to different efficiencies.

While the digestion technology was preliminarily selected, more options for power generation are incorporated within the model. The research focus is on electricity generation, so external heat recovery options (e.g., district heating) are not considered. For power generation, the model evaluates most commonly adopted internal combustion engines (ICEs) but also incorporates the opportunity of bottoming ICE cycles with an Organic Rankine Cycle (ORC) process (see Pöschl et al., 2012), i.e. recovering heat wasted by the ICE to produce electricity with an ORC turbine. As shown in Figure 4, the power flows from the ICE and ORC processes are calculated through electric efficiencies $\eta_{s}^{I C E}$ and $\eta_{s}^{O R C}$, multiplied by biogas energy flows from the AD and by waste heat flows from ICE, respectively, the latter being estimated through fixed waste heat to power output ratios $\alpha$. Efficiencies and ratios have been derived from the literature (Chinese et al., 2004; Pantaleo et al., 2013), considering the size classes defined in the model, and are reported in Table 5.

ICE efficiencies, in particular, range between $32 \%$ and $38 \%$. To obtain a preliminary estimate of technical potential for power generation, an average efficiency of $35 \%$ can be assumed for the engines most commonly used to date. A lower calorific value of $6.2 \mathrm{kWh} / \mathrm{Nm}^{3}$ is assumed for biogas in this study; therefore, its use in the engines mentioned would give an electric generation potential of approximately $404 \mathrm{GWh}$ /year based on the biogas potentials illustrated in Figures 1 and 
2. Assuming an average yearly operation time of 8000 hours (Lantz, 2012), this potential would correspond to a gross electric generation capacity of approximately $50.5 \mathrm{MW}$.

The net electricity generation capacity depends on the internal power demand of biogas plants, which is calculated as a proportion of gross output through coefficient $\delta_{\mathrm{p}}$. In this study, $\delta_{\mathrm{p}}$ has been fixed at $11 \%$ according to the Decree of the Italian Minister of Economic Development of 6 July 2012, which sets this value as a lump sum coefficient to calculate the net power output for which feed-in premiums and tariffs are paid out, independent of the actual consumption of single plants. Values reported in the literature are usually well below this threshold (e.g., between 3\% and 10\% according to Poeschl, 2010), so larger biogas ventures, selling electricity on the power market, could actually obtain a slightly higher profit, but for all of the types of plants in this study, it was decided to maintain the value mentioned above, which is deemed conservative. Coefficient $\delta_{\mathrm{H}}$ (reported in Table 5 and derived from Poeschl, 2010) is used to calculate heat flows required to sustain the mesophilic digestion process.

It is assumed that net generated electricity can always be fed into the electric grid and that no external capacity or demand constraints apply.

Energy production is constrained both by feedstock availability and by limitations on digestate spreading. The yearly production of biogas associated with each feedstock type $t$ depends on its volatile solid content $v s_{t}$ and on its biogas yield $y_{t}$, as reported in Table 4 for the selected digestion process. Amounts of digestate and of nitrates are calculated through coefficients $d_{t}$ and $N_{t}$, respectively, which vary depending on feedstock types and are reported in Table 4. For digestate management, several treatment options could be considered and included in system models (see Delzeit and Kellner, 2013). Within the boundaries of the examined system, only conventional digestate disposal practices are considered, i.e., storage in tanks and application of untreated 
digestate on agricultural land, and corresponding nitrogen content. Model constraints will guarantee that local limits on N/ha from manure (Figure 3) are respected for digestate disposal.

\subsubsection{Cost estimation}

Linearized investment cost functions are used in the model, and their intercept and slope are reported in Table 5.

Table 5. Investment cost function and main features of the technologies considered

The ORC cost function is derived from previous studies (Chinese et al., 2004), while costs of anaerobic digesters (ADs), including civil works and of internal combustion engines are obtained as a least squares interpolation of data gathered from constructors and reported in Figure 5.

Figure 5 Data and interpolations for plant cost estimation

Looking at coefficients of determination and at mean absolute percent errors (MAPEs) reported in Figure 5, the linear interpolation gives the best fit for $\mathrm{AD}$ construction costs. For internal combustion engines, the interpolation with a power function would be more accurate, but the inaccuracy is due mainly to the overestimation of the capital costs of the smallest engines $(50 \mathrm{~kW})$ with the linearized function: as shown in Figure 5, the mean absolute percent error of the linearized estimate is smaller if only engines of at least $150 \mathrm{~kW}$ are considered. For the sake of model simplicity and homogeneity, linearized functions were used to estimate all capital cost components. Although these functions do not rigorously represent economies of scale, they still account for decreasing specific costs of capital in that they include a size-independent fixed charge component $B^{T E C H}$ and have therefore been used in the literature to assess optimal plant size, e.g., by Walla and Schneeberger (2008) for biogas plants. As in the cited work, the range of available empirical data is limited (in this case, available data for digesters and internal combustion engines refer to capacities between $50 \mathrm{~kW}$ and $1000 \mathrm{~kW}$ ) and investment costs for plants over the upper bound of the range are 
obtained by extrapolation. Compared with the cost function by Walla and Schneeberger (2008), cost functions used in the present work lead mostly to higher estimates, which are, however, consistent with other findings from the Italian market (Pantaleo et al., 2013).

Operational costs included in the model are reported in Table 6.

Table 6. Operational cost coefficients

Manure purchase costs are set in the range of 4-6.5 €/t, depending on type, based on communications from local farmers. Although in biogas feasibility studies, manure purchase cost is often set to zero, as is especially the case when biogas power plants are owned by breeders, the high demand for animal manure in the last few years due to the rapid growth in the number of biogas plants in the region has increased the value of such feedstock.

Transport cost is subject to variation depending on technology adopted and the feedstock characterization: costs reported in Table 6 are obtained from local firms for a truck trailer with a capacity of $14 \mathrm{t}$ and a gas/oil price of $1.1 € / 1$, which is low compared with the general Italian market conditions due to tax abatements for agricultural usage. Plant operating hours are $8000 \mathrm{~h} / \mathrm{year}$, according to manufacturer's data and literature data (Pöschl et al., 2012). Similarly, direct labor cost varies in the range of $15,000-80,000 € /$ year, assuming an average labor cost of $40 \mathrm{k} € /$ person, with two full-time workers operating the larger power plant (more than $1 \mathrm{MW}$ ) and part-time workers for smaller power plants. Maintenance costs and insurance costs have been calculated as a proportion of gross electric energy produced using numerical values derived from the literature (Pantaleo, 2013; Walla et al., 2008; Riva et al., 2014) and from interviews with local plant managers. Finally, with regard to digestate management activities, transport costs are obtained for a tank wagon (with an average capacity of 20,000 liters) in which digestate is loaded and transported in the fields.

\subsection{Model development}


To model the energy system of concern, a mixed integer linear programming approach is used in this paper. To highlight the effect of changes in bioenergy promotion policies, former and forthcoming biogas incentive schemes are modeled with specific constraints in different model versions.

\subsubsection{Objective function}

The objective of the optimization model is to maximize yearly profits at the regional level, so the objective function (equation 1) is obtained as the sum of profits over all available locations $j$ :

$$
\begin{aligned}
& \operatorname{Max}\left\{\sum_{j} R_{j}+\right. \\
& \left.-\sum_{j}\left[\left(C_{j}^{\text {purc } B \text { BYP }}+C_{j}^{\text {harv } E C P}+C_{j}^{\text {disp_ } D}+C_{j}^{\text {main }}+C_{j}^{l a b}+C_{j}^{i n v}\right)\right]-\sum_{(i, j) \epsilon A}\left[\sum_{t} C_{i, j, t}^{t r_{-} B}+C_{i, j}^{t r_{-} D}\right]\right\}
\end{aligned}
$$

The first summand gives the total revenues for the plant located in $j$, and the second term includes operational costs associated with biogas plants such as procurement costs for animal byproducts $C_{j}^{\text {purc_BYP }}$ and of energy crops $C_{j}^{\text {harv } E C P P}$ obtained at site $j$, and local digestate disposal costs $C_{j}^{\text {disp_ } D}$, total maintenance, warding and insurance cost $C_{j}^{\text {main }}$ and labor cost $C_{j}^{l a b}$. Capital costs are multiplied by the uniform series capital recovery factor $f$ (calculated for a duration of 15 years and an interest rate $I=6 \%$ ) to express the capital costs as equivalent uniform annual costs $C_{j}^{i n v}$.

The third summand includes the biomass and the digestate transport costs between different locations $i$ and $j$, calculated as a summation on the set $A$ of all direct links between feasible locations $(i, j)$, with $i \neq j$. As shown in equations 2 and 3 , transportation costs consider empty running by doubling the distance dist $_{i, j}$ and the complexity of real connections between collection and delivery point by using a tortuosity factor $\tau$ of 1.33 (Overend, 1982).

$$
\begin{aligned}
& C_{i, j, t}^{t r_{-} B}=c_{t}^{t r_{-} B} \cdot Q_{t, i, j} \cdot \operatorname{dist}_{i, j} \cdot 2 \tau \\
& C_{i, j}^{t r_{-} D}=c_{t}^{t r_{-} D} \cdot Q_{i, j}^{D D^{N}} \cdot \operatorname{dist}_{i, j} \cdot 2 \tau
\end{aligned}
$$


While costs of transportation between different nodes are associated with links $(i, j)$, loading and unloading costs as well as costs for internal transport of biomass between supply areas and biogas plants located within the same site $j$ have been calculated at the node level, as a function of the acquired biomass or the amounts of disposed digestate. All these costs have been incorporated within summands $C_{j}^{\text {purc } c_{-} B Y P}, C_{j}^{\text {harv } E C P}$ and $C_{j}^{\text {disp } D}$, respectively, so that, for instance, $C_{j}^{\text {purc } B Y P}$ is calculated according to equation 4 as the product of quantities $Q_{t, j}^{p u r c_{-} B Y P}$ acquired in $j$ by the sum of unitary procurement and storage cost $c_{t}^{\text {purc }{ }_{-} B Y P}$ of animal byproducts, of their loading and unloading $\operatorname{cost} c^{l u_{-} B}$, and of their cost for internal transport within the $j^{\text {th }}$ supply area (from farms to a central reference point for collection), estimated as a function of an equivalent radius $\rho_{j}$ of municipality $j$.

$C_{j}^{\text {purc } \_B Y P}=\sum_{t} Q_{t, j}^{\text {purc } B Y P} \cdot\left(c_{t}^{\text {purc } \_B Y P}+c^{l u_{-} B}+c_{t}^{t r_{-} B} \cdot 2 \rho_{j} \tau\right)$

For various biomass types $t$, total transported quantities $Q_{t, i, j}$ are expressed in tons, while for digestate we chose to reference transportation and handling costs to its nitrogen content - e.g., using quantity $Q_{i, j}^{N_{-} D}$ to calculate transportation costs over link $(i, j)$ - because most balances and constraints deriving from the Nitrate Directive are based on that parameter.

As discussed in section 2.1.4, total annual maintenance cost is calculated as a proportion of gross electric energy $E l_{j}^{G R O S S}$ produced yearly at site $j$, as well as warding and insurance costs which are also included in $C_{j}^{\text {main }}$ :

$C_{j}^{\text {main }}=\left(c^{\text {maint_PLANT }}+c^{\text {ins_PLANT }}\right) \cdot E l_{j}^{G R O S S}$

Total annual labor cost is modeled according to equation 6 as a semi-fixed cost by using a special set of binary variables corresponding to plant size classes $s$.

$C_{j}^{l a b}=\sum_{s} c_{S}^{l a b_{-} P L A N T} X S_{S, j}^{P L A N T}$ 
The linearized investment cost function for plant components presented in Table 5 is expressed by equation 7 for each technology $T E C H$ as the sum of the size-independent cost component $b^{T E C H}$ $[€]$, multiplied by a binary variable $X_{j}^{T E C H}$, and the product of slope $m^{T E C H}[€ / \mathrm{kW}]$ and component capacity $S_{j}^{T E C H}$.

$C_{j}^{i n v}=f \cdot\left(b^{T E C H} \cdot X_{j}^{T E C H}+S_{j}^{T E C H} \cdot m^{T E C H}\right)$

\subsubsection{Revenue calculation and incentive modeling with constraints}

Total annual income is a function of total annual net electricity production $E l_{j}^{N E T}[\mathrm{kWh} / \mathrm{year}]$ and of marginal revenues, given by feed in tariffs or wholesale prices depending on the support scheme structure. Both Law 99/23 July 2009 and the Decree of 6 July 2012 basically introduce stepped tariffs, which can be modeled with special ordered sets of binary variables (Williams, 1999) introducing the corresponding constraints.

For the incentive scheme set until 2012, plants up to $999 \mathrm{~kW}$ may opt for Feed In Tariffs of 280 $€ / M W h$. Incomes for larger plants, which may benefit from Green Certificates and sell power at average electricity wholesale prices, are also modeled with an average power price of $223 € / \mathrm{MWh}$ (Table 2). The set of equations (8-11) imposes that the generated electricity $E l_{j}^{N E T}$ be either sold as $E l_{j}^{F I}$ at the Feed in Tariff $\operatorname{tar}^{F I}$ or as $E l_{j}^{G C}$ at average tariff $\operatorname{tar}^{G C}$ equivalent to Green Certificates; equations 10 and 11, in particular, constrain power sales to fall under either the first or the second tariff class while respecting the capacity limitation.

$E l_{j}^{N E T}=E l_{j}^{F I}+E l_{j}^{G C}$

$R_{j}=E l_{j}^{F I} \cdot \operatorname{tar}^{F I}+E l_{j}^{G C} \cdot \operatorname{tar}^{G C}$ 
$X T_{j}^{F I}+X T_{j}^{G C} \leq 1$

$S_{j}^{P L A N T} \leq 999 * X T_{j}^{F I}+M^{P L A N T} * X T_{j}^{G C}$

The new tariff scheme takes into account feedstock mix and plant size. Feed in Tariff $\operatorname{tar}^{E C P}$ or $\operatorname{tar}^{B Y P}$ apply when energy crops or animal byproducts prevail, respectively. Equation 12 represents the case of simultaneous utilization of $Q_{J}^{E C P}$ and $Q_{J}^{B Y P}$, specifying that the tariff for energy cropbased power generation $\operatorname{tar}^{E C P}$ applies when the total share of animal byproducts is smaller or equal to $30 \%$ of the total substrates. Mathematically:

$\left\{Q_{J}^{E C P}-\left[\left(Q_{J}^{E C P}+Q_{J}^{B Y P}\right) \cdot 0.3\right]\right\}-\left(M \cdot X B_{j}\right) \leq 0$

imposes the $30 \%$ share limit to energy crop mass flows when $X B_{j}$ equals 0 , which implies that $X B_{j}$ must be 1 when energy crop flows exceed the limit share.

As shown in Table 2, five size classes, here represented by sets $s$, are introduced for stepped tariffs. For each size class, corresponding binary variables $X S_{s, j}^{P L A N T}$ have been introduced, equaling1 when capacity $S_{j}^{P L A N T}$ of the $j^{\text {th }}$ plant is lower than or equal to the upper capacity bound $S B_{s}$ for size class $s$ and higher than the upper capacity bound $S B_{s-1}$ for size class $s-1$.

Binary variables $X T_{s, j}^{E C P}$ and $X T_{s, j}^{B Y P}$ are also introduced to signal whether a plant falls within the energy crops or the animal byproduct bonus class and used in equation 13 to guarantee that each feasible plant falls within a single size and substrate bonus class. Equations 14 and 15 impose that if $X B_{j}=1$, i.e., energy crops exceed the limit share in plant $j$, corresponding $(E C P)$ feed in tariff applies.

$\sum_{s}\left(X T_{s, j}^{E C P}+X T_{s, j}^{B Y P}\right) \leq 1$

$X B_{j} \leq \sum_{s} X T_{s, j}^{E C P}$

$\sum_{s} X T_{s, j}^{B Y P} \leq 1-X B_{j}$ 
The correspondence between plant capacities and binary indicators of tariff classes is guaranteed by the set of equations 16-18. Equations 19-21 subordinate electricity production to the installation of energy conversion equipment and link it to size and substrate mix classes.

$S_{j}^{P L A N T}-\left(S B_{S}+1\right) \cdot X S_{S, j}^{P L A N T} \geq 0$

$S_{j}^{P L A N T}+M^{P L A N T} \cdot X S_{S, j}^{P L A N T} \leq M^{P L A N T}+S B_{S+1}$

$X T_{s, j}^{E C P}+X T_{s, j}^{B Y P}=X S_{s, j}^{P L A N T}$

$X S_{S, j}^{P L A N T} \leq X_{j}^{I C E}$

$E l_{s, j}^{E C P} \leq M^{P L A N T} \cdot h^{P L A N T} \cdot X T_{s, j}^{E C P}$

$E l_{s, j}^{B Y P} \leq M^{P L A N T} \cdot h^{P L A N T} \cdot X T_{s, j}^{B Y P}$

The yearly net electricity generation $E l_{j}^{N E T}$ is calculated as the sum of $E l_{s, j}^{E C P}$ and $E l_{s, j}^{B Y P}$ over size and substrate mix classes, and revenues are thus calculated according to equation 22 as:

$R_{j}=\sum_{s}\left(E l_{s, j}^{E C P} \cdot \operatorname{tar}_{s}^{E C P}+E l_{s, j}^{B Y P} \cdot \operatorname{tar}_{s}^{B Y P}\right)$

\subsubsection{Energy and material flows balances}

While the equations above link power generation to the tariff scheme, energy and mass flow balances are needed to ensure correspondence between the economic model and the energy conversion systems.

Binary variables $\mathrm{X}_{j}^{A D}, \mathrm{X}_{j}^{I C E}$ and $\mathrm{X}_{j}^{O R C}$ are introduced, equalling 1 if an anaerobic digester, an ICE or ORC technology are adopted at site $j$. In particular, an ICE can be installed only if a digester exists and ORC construction is subordinated to ICE existence according to equations 23-24. 
$X_{j}^{A D} \geq \mathrm{X}_{j}^{I C E}$

$\mathrm{X}_{j}^{I C E} \geq X_{j}^{O R C}$

Calculation of net generated electricity is performed according to equations 25-28, using coefficients $\alpha$ and factors $\delta^{\mathrm{P}}$ and $\delta^{\mathrm{H} \text {, }}$ as explained in section 2.1.3, to calculate the waste heat flows from the ICE and the plant self-consumption of electricity and of heat. Only if ORC equipment is installed (equation 27), additional electricity production $E l_{j}^{O R C}[\mathrm{kWh} /$ year $]$ is calculated (equation 28) as the product of ORC electrical efficiency $\eta^{O R C}$ and heat recovered from engine $H_{j}^{I C E}$ $[\mathrm{kWh} /$ year $]$, reduced by factor $\left(1-\delta^{H}\right)$ to account for process heat demand.

$$
\begin{aligned}
& E l_{j}^{N E T}=E l_{j}^{G R O S S} \cdot\left(1-\delta^{P}\right) \\
& E l_{j}^{G R O S S}=E l_{j}^{I C E}+E l_{j}^{O R C} \\
& E l_{j}^{O R C} \leq X_{J}^{O R C} \cdot M^{P L A N T} \cdot h^{P L A N T} \\
& E l_{j}^{O R C}=\eta^{O R C} \cdot\left(E l_{j}^{I C E} \cdot \alpha \cdot\left(1-\delta^{H}\right)\right)
\end{aligned}
$$

Introducing engine size classes $s$ with equations similar to 16-17, equation 29 accounts for the increase in the electrical efficiency of internal combustion engines with growing size as reported in Table 5. Equation 30 expresses total biogas production $B G_{j}\left[\mathrm{Nm}^{3} /\right.$ year $]$ as a function of volatile solids $v s$ and of biogas yields $y$ of each animal byproduct type $t$ and of the considered energy crop (maize) given in Table 4.

$$
\begin{aligned}
& E l_{j}^{I C E}=\sum_{s}\left(\eta_{s}^{I C E} * X S_{s, j}^{I C E}\right) * B G_{j} * k^{B G} \\
& B G_{j}=\sum_{t}\left(Q_{t, j}^{B Y P} \cdot v s_{t}^{B Y P} \cdot y_{t}^{B Y P}\right)+\left(Q_{j}^{E C P} \cdot v s^{E C P} \cdot y^{E C P}\right)
\end{aligned}
$$


As a function of the feedstock, equation 30 associates the energy flows with the corresponding material flows. Material flow balances have the typical expression used in solid biomass supply chain optimization models (see, e.g., Kim et al., 2011; Kiraly et al., 2013), given by equation 31 for a generic feedstock, in this case an energy crop, and in equation 32 for digestate, in terms of the equivalent nitrogen content, constrained according to the Nitrate Directive through equation 33.

$$
\begin{aligned}
& Q_{j}^{\text {harv_ECP }}+\sum_{i \in A(i, j)} Q_{i, j}^{E C P}=Q_{j}^{E C P}+\sum_{k \in A(j, k)} Q_{j, k}^{E C P} \\
& \sum_{t} Q_{t, j}^{B Y P} \cdot d_{t}^{B Y P} \cdot N_{t}^{B Y P}+Q_{j}^{E C P} \cdot d^{E C P} \cdot N^{E C P}+\sum_{i \in A(i, j)} Q_{i, j}^{N_{-} D}=Q_{j}^{N_{-} \text {spread }}+\sum_{k \in A(j, k)} Q_{j, k}^{N_{-} D} \\
& Q_{j}^{N \_s p r e a d} \leq Q_{j}^{\text {maxN_spread }}
\end{aligned}
$$

\section{Model implementation, results and discussion}

The model was implemented in the algebraic language GAMS, and solved with the commercial solver CPLEX®. To assess the effects of energy policies, four scenarios of analysis were created. The previous support scheme (PSS) scenario has the features and the constraints of the 2009 tariff scheme, while in the future support scheme (FSS) scenario, the energy prices are differentiated by the plant classes and the feedstock mix, according to the 2012 tariff scheme. For the sake of comparison, two cost minimization scenarios are added, named CM_PSS and CM_FSS, where a mandatory share of electricity production is fixed, corresponding to the economic potentials calculated by the optimization procedure for scenarios PSS and FSS, respectively. Thus, minimum cost supply chain configurations are identified, and minimum production costs to obtain the same energy output are estimated, which would lead to maximum profits in the absence of stepped in tariffs. Comparing such configurations and costs with those obtained under the PSS and the FSS incentive scenarios, the impact of the incentive mechanisms on the optimal size of biogas plants and 
on the energy costs are highlighted. The main results for the analyzed scenarios are summarized in Table 7.

Table 7. Optimization results under defined scenarios

\subsection{Changes in optimal solutions between PSS and FSS scenarios}

In the PSS scenario, the additional economic potential reaches almost $38 \mathrm{MW}$, more than 4 times as much as existing total capacity, and 38 new plants would be feasible, with an average size of 998 $\mathrm{kW}$ and virtually no variance: the homogenization process described in the literature is thus confirmed by the model. In the FSS scenario, the additional capacity would be $5.1 \mathrm{MW}$ - that is approximately $60 \%$ of the existing capacity - spread over seventeen $300 \mathrm{~kW}$ plants. Homogenization therefore seems probable also in the future, although stopping at a smaller optimal capacity. Although economically viable from an NPV viewpoint, the implementation of such additional capacity seems unlikely looking at other profitability indicators calculated at the systems level. Average payback time would increase from 3.6 years in the PSS scenario to almost 9 years in the FSS scenario, and the IRR would decrease from more than $30 \%$ (PSS) to $7 \%$ (FSS). The assumption of an investment duration of 15 years may be restrictive in evaluating the FSS scenario, in that incentives between the fifteenth and the twentieth year are neglected. Actually, neglecting additional expenses for plant revamping and special maintenance after 15 years, indicators calculated for a 20 year investment duration exhibit an increase (reaching total NPVs of approximately 17 million $€$ in 20 years, against almost 1.8 million $€$ in 15 years, and IRR of $9 \%$, against 7\% in 15 years, see starred values in Table 7), which is, however, so small compared with the profitability chances under the PSS (with total NPVs of approximately 320 million $€$ in 15 years and IRR of approximately 30\%) and so uncertain that attracting new investors under new conditions seems very challenging. In fact, low margins under the FSS also make investments much more 
sensitive to variations in uncertain parameters than under the PSS, as shown in Figure 6 and Figure 7. Analyzing the influence of each parameter with a change of $\pm 20 \%$ from baseline values, maximum variations in NPV at regional level are found to be approximately $\pm 250 \%$ under the FSS, against $\pm 40 \%$ under the PSS. Capital costs and efficiency have the largest influence, indicating that improving the technology and its market prices, which as mentioned earlier were higher in Italy than in neighboring countries, could improve prospects for biogas plant development even in the future. Both in the PSS and FSS scenario, NPV is also significantly affected by variations in maintenance costs $( \pm 12 \%$ under PSS, $\pm 110 \%$ under FSS), which represent the major shares of operational costs (Figure 8), and in byproduct costs $(60 \%$ to $+70 \%$ under FSS and-20\% to+12\% under PSS, in spite of their limited share in feedstock mix in this scenario). The contribution of transportation costs to operational costs ranges between 5\% under PSS scenario and $17 \%$ under CM_FSS scenario (Figure 8), and their variation has a limited influence on NPVs $(-3 \%$ to $+2 \%$ under PSS, $-5 \%$ to $+3 \%$ under FSS) because of the low cost of gas and oil for agricultural transport.

Figure 6. Parameter sensitivity on system NPV under the previous support scheme

Figure 7. Parameter sensitivity on system NPV under the future support scheme

Figure 8. Operational cost structure under different scenarios

Thus, the estimate of annual net electricity production of $95 \mathrm{GWh}$ under the FSS scenario (compared with 328 GWh with PSS), contributing less than $1 \%$ to regional RES-E targets, may even be optimistic. Consequently, even though the money flows from biogas incentives remain the main source of revenues for biogas plants in most scenarios (only in the hypothetical CM_FSS their contribution, i.e., 4.43 M€/year, falls below $50 \%$ of total revenues, i.e., $11.36 \mathrm{M} € /$ year), their estimated reduction from approximately 77 million Euro in the PSS scenario to less than 11 million 
Euro in the FSS scenario (Table 7) might be more remarkable, in that even the restricted number of economically feasible plants might not be commissioned under the future scenario.

In addition to reducing the additional potential for non-cogenerative agricultural biogas plants by a factor of almost 8 , the new tariff system also minimizes chances for maize as a substrate. As shown in Table 7, under the old scheme the average weight share of manure was approximately $20 \%$ in the optimized solution, with $80 \%$ coming from maize silage, with a total substrate production of approximately $687 \mathrm{kt} / \mathrm{year}$. Under the new tariff scheme, viable biogas plants would use animal manure as a single feedstock. The estimated optimal solution with $100 \%$ manure-based plants is an extreme, depending on the fact that the linear model cannot account for positive synergisms improving biogas yield in co-digestion of different substrates, but the results indicate that maize production for biogas generation is not affordable under the new support scheme.

Due to the lower energy density of animal manure, its enhanced use as a substrate results in a higher impact of biomass and digestate transportation and management on total operational costs (Figure 8). In spite of plant size reduction, the surface of feedstock supply and digestate spreading areas grows. As reported in Table 7 and highlighted graphically in Figures 9 and 10, in the case of cattle manure, average supply areas increase from $124 \mathrm{~km}^{2}$ under the PSS to $215 \mathrm{~km}^{2}$ under the FSS.

Figure 9. Plant locations, capacities and cattle manure supply areas - PSS Scenario

Figure 10. Plant locations, capacities and cattle manure supply areas - FSS Scenario

The environmental impact from transportation is thus likely to increase and even though the supply distances usually remain below limits for positive energy balances and net environmental benefits identified in the literature $(22 \mathrm{~km}$ and $64 \mathrm{~km}$ for cattle manure, respectively, according to Pöschl et al., 2012), single occurrences or transition phases deserve further investigation. Also areas for digestate spreading increase from $61 \mathrm{~km}^{2}$ under the PSS to $89 \mathrm{~km}^{2}$ under the FSS: this is a 
consequence of the lower energy density of manure as a feedstock, which results in larger input and byproduct quantities, as found also in similar work by Delzeit and Kellner (2013). Compared with feedstock supply, areas for digestate management are smaller, and it is usually easier to respect distance limits for net environmental benefits (e.g., $95 \mathrm{~km}$ for cattle manure and $19 \mathrm{~km}$ for maize silage according to Pöschl et al., 2012). The Nitrate Directive constraints for digestate spreading are a limiting factor under the PSS (saturation is almost 100\%): local authorities should have directed particular attention to digestate management specifications of biogas projects and more advanced digestate management techniques would have been an option in that scenario. Under the FSS, estimated saturation decreases significantly; the viability of techniques for nitrogen content reduction in digestate could be evaluated in the light of specific incentives in the FSS, but there would be most likely less pressure to adopt them as fewer plants would be commissioned. Authorities should rather concentrate their attention on the origin of substrates feeding prospective plants.

\subsection{Changes in optimal solutions between profit maximizing and cost minimizing scenarios}

Pursuing the minimization of the costs of electricity production as in the CM_PSS and CM_FSS scenarios would be rational, in that the target bioenergy shares would be obtained at the highest economic efficiency. Both under the CM_PSS and CM_FSS scenarios, the use of manure increase and the optimal plant size would increase, with a remarkable expansion of feedstock supply areas (469 $\mathrm{km}^{2}$ in the CM_FSS scenario compared with $215 \mathrm{~km}^{2}$ in the corresponding FSS scenario). The digestate disposal area remains almost unchanged, thanks to lower substrate consumption associated with better efficiency. Larger plants not only reap economies of scale but also benefit from higher power generation efficiency because larger internal combustion engines are more efficient and because the minimum capacity for technical and economic feasibility of ORC bottoming cycles can be achieved. Optimal sizes and combinations of technologies depend on local feedstock availability, 
but optimal solutions include only bottoming cycles with a power capacity of at least $500 \mathrm{~kW}$, which can be sustained by the heat recovery from the ICEs with a power capacity of at least 2900 $\mathrm{kW}$. Such large plants are, however, introduced only in cost minimization scenarios, which do not account for feed in tariffs in their objective function. Both under the previous and the future biogas support schemes, better efficiency and lower specific costs do not compensate for reduced values of FITs (or of GCs, which generate the main share of revenues in the CM_PSS scenario) introduced for larger capacities. Because of lower revenues from support mechanisms, the NPVs are significantly smaller and the payback times are longer under cost minimization scenarios than under the corresponding profit maximization scenarios. Under the CM_FSS scenario, the investment does not even pay off, even though the electricity production cost is at its minimum, with $0.171 € / \mathrm{kWh}$.

Comparing the profit maximization and the corresponding cost minimization scenarios, the estimated increase of levelized electricity costs due to support mechanisms is moderate: under the PSS, average electricity cost grows by approximately $12 \%$, from $0.187 € / \mathrm{kWh}$ in the CM_PSS to $0.209 € / \mathrm{kWh}$ in the PSS scenario, while under the FSS average electricity costs grow by approximately $8 \%$, from $0.171 € / \mathrm{kWh}$ to $0.185 € / \mathrm{kWh}$ under the CM_FSS and the FSS scenarios, respectively. These additional expenses are associated with higher investments (difference between investment costs under profit maximization and corresponding cost minimization scenarios is approximately 17 million $€$ under the PSS, approximately 12 million $€$ under the FSS) and smaller plants, which usually benefit from higher social acceptance. Cost minimization - which is likely to be pursued in case of a flat Feed in Tariff - is associated with higher variability in the optimal size, while a stepped Feed in Tariff causes homogenization of plant capacity under both support schemes.

\section{Conclusions and policy implications}


By applying the model to the selected case study, the incentive mechanism in force in Italy until 2012 was shown to foster the homogenization process towards so-called "entrepreneurial farms" (Carrosio, 2013), that is, a proliferation of $999 \mathrm{~kW}$ biogas power plants, based on maize as a feedstock and without external uses of the heat produced as a byproduct. Under former support schemes, the economic potential (46.17 MW) for electricity from agricultural biogas in the area of concern would have reached more than $90 \%$ of the technical potential (50.5 MW), generating environmental concerns about the saturation of available areas for digestate disposal and about the social acceptance of a high spatial density of plants (46 plants in 131 municipalities or $4000 \mathrm{~km}^{2}$ ). However, based on optimization results analyzed in this paper, the cut in Feed-in Tariffs introduced in 2012, which was milder for small scale manure-based plants and more severe for energy cropbased plants at approximately $1 \mathrm{MW}$, will leave hardly any room for entrepreneurial farms as they used to be. In the area examined, only manure-based small-scale plants will be feasible without external use of the heat. Because the area of concern shares the typical features of Northern Italy as a whole, and the maize productivity reaches its highest values here, we can conclude that there will be limited room for the maize silage as a biogas feedstock under the new support scheme. A pressure towards homogenization will most likely continue, although toward smaller optimal plant sizes. Environmental concerns in this case regard the wide extension of animal byproduct supply areas, as the spatial density of manure production is relatively low, and the contribution of transportation costs to operational costs is limited. Distance limits for energy and environmental benefits from biogas generation risk being exceeded, undermining the rationale for supporting biogas and particularly manure-based electricity production.

The model used in this analysis focuses on economic optimization, while energy and environmental performances are considered only as external reference values based on the literature. Further 
developing biogas supply chain models to account for energy and environmental performance with a multi-objective approach is a goal for future research.

In the examined context, a considerable reduction in investments in biogas to electricity can be expected.

In turn, the existing capacity is well below the economic potentials for biogas power estimated under the previous, favorable support scheme. This observation has two implications:

- Policy effects indicate that the long-term outlook for the biogas to electricity market in Italy may be worse than estimated. Recent legislation, i.e., a Decree of the Minister for Economic Development issued on 5 December 2013, introduced incentives for biomethane injection and biomethane as a transportation fuel in Italy for the first time. Further developing biogas supply chain models to estimate potentials for different biogas utilization scenarios under the environmental considerations would be useful to provide a better understanding of future prospects for agricultural biogas in Italy;

- Policy modeling draws attention to the limitations of bottom up models and their excessive "optimism" in estimating costs and difficulties of technological change, e.g., for $\mathrm{CO}_{2}$ reduction, in that they do not capture all the risks, social costs and barriers perceived by consumers and firms confronted with new technologies (Rivers and Jaccard, 2005). Hybrid models and a more cautious evaluation of interest rates based on empirical research could be a means to achieve better prediction accuracy. 


\section{Acknowledgments}

The research activity by Ms. Patrizio is funded by a doctoral fellowship of the Italian Ministry of University, Research and Education. We are indebted to two anonymous referees for their valuable comments, criticisms and suggestions. We also acknowledge our Master degree students, particularly Mr. Antonio Mussutto and Mr. Paolo Mior, for their cooperation in the data gathering process.

\section{References}

An H., Wilhelm W.E., Searcy S.W. (2011), Biofuel and petroleum-based fuel supply chain research: A literature review. Biomass and Bioenergy, Volume 35(9), Pages 3763-3774

Banzato D. (2013). Analisi tecnico economica della filiera del biogas a seguito del D.M. 6 luglio 2012. Opportunità e limiti per l'impresa zootecnica. Ph.D. thesis available at http://paduaresearch.cab.unipd.it/5596/1/Banzato_D.pdf

Bekkering J., Broekhuis A.A., Van Gemert V.J.T., Hengeveld E.J. (2010). Balancing gas supply and demand with a sustainable gas supply chain - A study based on field data. Applied Energy, Volume 111, Pages 842- 852.

Bojesen M, Birkin M., Clarke G.,(in press). Spatial competition for biogas production using insights from retail location models, Energy (2014). http://dx.doi.org/10.1016/j.energy.2013.12.039

Boulamanti A.K., Maglio S.D., Giuntoli J., Agostini A., (2013). Influences of different practices in biogas sustainability. Biomass and Bionergy, Volume 53, Pages 149-161

Capponi S., Fazio S., Barbanti L., (2011). $\mathrm{CO}_{2}$ savings affect the break-even distance of feedstock supply and digestate placement in biogas production. Renewable Energy, Volume 37(1), Pages 4552.

Carrosio G., (2013). Energy production from biogas in the Italian countryside: Policies and organizational models. Energy Policy, Volume 63, Pages 3-9. 
Chinese D., Meneghetti A., Nardin G., (2004). Diffused introduction of Organic Rankine Cycle for biomass-based power generation in an industrial district: a systems analysis. International Journal of Energy Research. Volume 28 (11), Pages 1003-1021.

CRPA spa (2008). Biogas: Analisi di fattibilità tecnico-economica. CRPA NOTIZIE , Opuscolo 6.20 - N. 4/2008. http://www.crpa.it/media/documents/crpa_www/Pubblicazi/OpuscoliC/Archivio_2008/CRPA_4_2008_ultima_versione.pdf

CRPA spa (2012). Conoscere per competere- il digestato, un utile sottoprodotto del biogas. Centro divulgazione agricola. Settembre 2012.

http://www.crpa.it/media/documents/crpa_www/Pubblicazi/conoscer\&competere/_conoscerexcomp eter_n4.pdf

De Meyer A., Cattrysse D., Rasinmäki J., Van Orshoven J., (2014). Methods to optimise the design and management of biomass-for-bioenergy supply chains: A review. Renewable and Sustainable Energy Reviews, Volume 31, Pages 657-670.

Delzeit R., Kellner U., (2013). The impact of plant size and location on profitability of biogas plants in Germany under consideration of processing digestates. Biomass and Bioenergy, Volume 52, Pages 43-53.

Delzeit R., Britz W., Holm-Müller K., (2011). Modelling regional input markets with numerous processing plants: The case of green maize for biogas production in Germany. Environmental Modelling \& Software, Volume 32, Pages 74-84.

Enea (2009), Analisi e stima quantitativa della potenzialità di produzione energetica da biomassa digeribile a livello regionale. Studio e sviluppo di un modello per unità energetiche. Report RSE/2009/182.

http://www.enea.it/it/Ricerca_sviluppo/documenti/ricerca-di-sistema-elettrico/celle-acombustibile/rse182.pdf

Gan J., Smith C.T. (2011). Optimal plant size and feedstock supply radius: A modeling approach to minimize bioenergy production costs. Biomass and Bioenergy, Volume 35(8), Volume 3350-3359.

Galeotti M, (2012). Energia Rinnovabile, oltre il costo degli incentive. IEFE, Centre for Research on Energy and Environmental Economics and Policy

Gebrezgabher S.A., Meuwissen M.P.M, Prins B.A.M, Oude Lansink A., (2010). Economic analysis of anaerobic digestion-A case of Green power biogas plant in The Netherlands. NJAS Wageningen Journal of Life Sciences, Volume 57 (2), Pages 109-115.

GSE (2008). Statistiche sulle fonti rinnovabili in Italia, Anno 2008.

http://www.gse.it/it/Statistiche/Simeri/fer/DocumentLibraryStatisticheFER/STATISTICHE- 
2008.pdf

GSE (2009). Impianti a fonti rinnovabili, rapporto statistico 2009.

http://www.gse.it/it/Statistiche/Simeri/fer/DocumentLibraryStatisticheFER/Statistiche_2009.pdf

GSE (2010). Impianti a fonti rinnovabili, rapporto statistico 2010.

http://www.gse.it/it/Statistiche/Simeri/fer/DocumentLibraryStatisticheFER/Statistiche_Rinnovabili _2010.pdf

GSE (2011). Impianti a fonti rinnovabili, rapporto statistico 2011.

http://www.gse.it/it/Statistiche/Simeri/fer/DocumentLibraryStatisticheFER/Statistiche\%20Rinnova bili\%202011.pdf

Gold S., Seuring S., (2011). Supply chain and logistics issues of bio-energy production. Journal of Cleaner Production, Volume 19 (1), Pages 32-42.

Gunnarsson C., Vågström L., Hansson P-A. (2008). Logistics for forage harvest to biogas production-Timeliness, capacities and costs in a Swedish case study. Biomass and Bioenergy, Volume 32 (12), Pages 1263-1273.

Hahn H., Rutz D.,Ferber E., Kirchmayer F., (2010). Examples for financing of biogas projects in Germany, Austria, The Netherlands, Denmark and Italy. IEE Project 'BiogasIN', D.3.2.,WP3. http://www.biogasin.org/files/pdf/Financing_of_biogas_projects_in_top_5_EU_countries.pdf

Haas R., Panzer C., Resch G., Ragwitz M., Reece G., Held A., (2011). A historical review of promotion strategies for electricity from renewable energy sources in EU countries. Renewable and Sustainable Energy Reviews, Volume 15 (2), Pages 1003-1034.

ISTAT (2011), National Statistics Institute, Data from the VI national agricultural census survey, http://agri.istat.it/jsp/dawinci.jsp?q=plC020000020000073200\&an=2011\&ig=1\&ct=244\&id=15A|1 $\underline{8 \mathrm{~A} \mid 25 \mathrm{~A}}$

Karellas S., Boukis I.,Kontopoulos G., (2010). Development of an investment decision tool for biogas production from agricultural waste. Renewable and Sustainable Energy Reviews. Volume 14, Pages 1273-1282.

Kim J., Matthew J., Realff M., Lee J., Whittaker C., Furtner L., (2011). Design of biomass processing network for biofuel production using an MILP model, Biomass and Bioenergy, Volume 35(2), Pages 853-871.

Kiraly A., Pahor B., Kravanja Z. (2013), Achieving energy self- sufficency by integrating renewables into companies' supply network. Energy, Volume 55, Pages 46-57.

Lantz M., (2012). The economic performance of combined heat and power from biogas produced from manure in Sweden - A comparison of different CHP technologies. Applied Energy, Volume 98, Pages 502-511.

Lorenzoni A. (2003), The Italian Green Certificates market between uncertainty and opportunities. 
Energy Policy, Volume 31 (1), Pages 33-42.

Mafakheri F., Nasiri F., (2014). Modeling of biomass-to-energy supply chain operations: Applications, challenges and research directions. Energy Policy,Volume 67, Pages 116-126.

Magnani N.,(2012). Exploring the Local Sustainability of a Green Economy in Alpine Communities, Mountain Research and Development, 32(2), Pages 109-116.

Overend R.P. (1982). The average haul distance and transportation work factors for biomass delivered to a central plant. Biomass, Volume 2(1), Pages 75-79.

Pantaleo A., De Gennaro B., Shah N. (2013), Assessment of optimal size of anaerobic co-digestion plants: An application to cattle farms in the province of Bari (Italy). Renewable and Sustainable Energy Reviews, Volume 20, Pages 57-70.

Perez R., Zweibel K., Hoff T.E., (2011). Solar power generation in the US: Too expensive, or a bargain? Energy Policy, Volume 39, Pages 7290-7297.

Popp J., Lakner Z., Rákos H., Fári M. (2014). The effect of bioenergy expansion: Food, energy, and environment. Renewable and Sustainable Energy Reviews. Volume 32, Pages 559-578.

Pöschl M., Ward S., Owende P. (2010). Evaluation of energy efficiency of various biogas production and utilization pathways. Applied Energy, Volume 87(11), Pages 3305-3321.

Pöschl M., Ward S., Owende P. (2012). Environmental impacts of biogas deployment - Part II: life cycle assessment of multiple production and utilization pathways. Journal of Cleaner Production, Volume 24, March 2012, Pages 184-201

Rivers N., Jaccard M, (2005). Combining Top-Down and Bottom-Up Approaches To Energy-Economy Modeling Using Discrete Choice Methods. The Energy Journal, Volume 26 (1), Pages 83-106

Sathaye J., Sanstad A. H. (2004). Bottom-up energy modeling. Reference Module in Earth System and Environmental Science, Pages 251-264.

Schmidt J., Leduc S., Dotzauer E., Schmid E., (2011). Cost-effective policy instruments for greenhouse gas emission reduction and fossil fuel substitution through bioenergy production in Austria.Energy Policy. Volumes 3261-3280

Sharma B, Ingalls R. G., Jones C.L., Khanchi A. (2013) Biomass supply chain design and analysis: Basis, overview, modeling, challenges, and future. Review Article. Renewable and Sustainable Energy Reviews, Volume 24, Pages 608-627.

Sorda G., Sunak Y., Madlener R., (2013). An agent-based spatial simulation to evaluate the promotion of electricity from agricultural biogas plants in Germany. Ecological Economics, Volume 89, Pages 43-60.

Stürmer B., Schmidt E., Eder M.W., (2011). Impacts of biogas plant performance factors on total 
substrate costs. Biomass and Bioenergy, Volume 35(4), Pages 1552- 1560.

Thuesen G.J., Fabrycky W.J., (1993). Engineering Economy. Prentice-Hall Inc., Englewood Cliffs, NJ

Thorin E., Lindmark J., Nordlander E., Odlare M., Dahlquist E., Kastensson J., Leksell N., Pettersson C-M., (2012). Performance optimization of the Växtkraft biogas production plant. Applied Energy, Volume 97, Pages 503-508.

Tricase C., Lombardi M. (2009). State of the art and prospects of Italian biogas production from animal sewage: Technical-economic considerations. Renewable Energy, Volume 34 (3), Pages 477485

Walla C., Schneeberger W., (2008). The optimal size of a biogas plant. Biomass and Bioenergy, Volume 32(6), Pages 551-557.

Williams H.P. (1999). Model building in mathematical programming. John Wiley and Sons, Chichester, 1999.

Yiridoe E.C., Gordon r., Brown B.B., (2009). Nonmarket co-benefits and economic feasibility of on-farm biogas energy production. Energy Policy, Volume 37(3), Pages 1170-1179.

Yue D., You F, Snyder S.W., (in press). Biomass-to-bioenergy and biofuel supply chain optimization: Overview, key issues and challenges. Computers and Chemical Engineering (2014).http://dx.doi.org/10.1016/j.compchemeng.2013.11.016 